\title{
Development of a Method for Detecting Coxiella burnetii in Cheese Samples
}

\author{
Akihiko HIRAI $^{1) *}$, Akiko NAKAMA ${ }^{1)}$, Takashi $\mathrm{CHIBA}^{1)}$ and Akemi KAI ${ }^{1)}$ \\ ${ }^{1)}$ Department of Microbiology, Tokyo Metropolitan Institute of Public Health, 3-24-1 Hyakunin-cho, Shinjuku-ku, Tokyo 169-0073, \\ Japan
}

(Received 17 January 2011/Accepted 26 September 2011/Published online in J-STAGE 7 October 2011)

\begin{abstract}
Coxiella burnetii is the causative agent of Q fever, and the main route of infection in humans is inhalation of contaminated aerosols. Although oral transmission by contaminated raw milk or dairy products is also a possible route of human infection, there have been few studies investigating the presence of $C$. burnetii in dairy products. We developed a new method of extracting DNA from cheese and detecting C. burnetii DNA in cheese samples with a nested PCR assay. The limit of detection was $6.0 \times 10^{2}$ C. burnetii particles per gram. We subsequently used this method to examine the presence of $C$. burnetii in cheese at commercial markets in Tokyo from June 2005 to December 2008. Twenty-eight of 147 cheese samples were found to be positive for C. burnetii DNA. However, when we assessed the viability of $C$. burnetii by inoculating mice with DNA-positive samples, all of the samples were found to be negative. Thus, the viability of $C$. burnetii appears to have been lost in these cheese samples.
\end{abstract}

KEY WORDS: cheese, contamination, Coxiella burnetii, nested PCR.

doi: 10.1292/jvms.11-0023; J. Vet. Med. Sci. 74(2): 175-180, 2012

Coxiella burnetii is the causative agent of $\mathrm{Q}$ fever in humans and of coxiellosis in animals. It is a Gram-negative, obligate intracellular bacterium that has been found worldwide, except in New Zealand. It affects a variety of arthropods, birds and domestic and wild mammals, as well as humans $[11,16]$. Q fever manifests as either acute or chronic illness. The acute disease is usually a flu-like, selflimiting illness accompanied by fever, headache and myalgia. The chronic disease occurs in approximately $1-3 \%$ of patients; endocarditis and hepatitis are the most frequent and serious manifestations $[11,16]$.

The major source of infection in humans is the inhalation of contaminated aerosols or dust containing C. burnetii. Infected animals such as goats, sheep, cattle, dogs and cats excrete $C$. burnetii at high concentrations in their urine, feces, milk and birth products $[8,11,16]$. These infected animals are considered the primary source of transmission to humans. In the Netherlands, dairy goats and sheep farms have been suggested to be sources of Q fever outbreaks [4].

Consumption of contaminated raw milk and dairy products have also been proposed as sources of human infection. A Q fever outbreak occurred in France in 1987, and a serological survey suggested that a potential source was unpasteurized dairy products [5]. Based on another case that occurred in Newfoundland in 1999, a serological survey and an epidemiological study suggested that consumption of cheese made from goat milk was a significant risk factor for Q fever [9]. Moreover, a 2-year epidemiological study of hospitalized children in Greece showed that consumption of cheese from rural areas increased the risk for Q fever [15].

\footnotetext{
* Correspondence to: Hirai, A., Department of Microbiology, Tokyo Metropolitan Institute of Public Health, 3-24-1 Hyakunin-cho, Shinjuku-ku, Tokyo 169-0073, Japan. e-mail: Akihiko_Hirai@member.metro.tokyo.jp
}

C2012 The Japanese Society of Veterinary Science
C. burnetii is inactivated by pasteurization of commercial milk [27]. In contrast, cheese manufacturing is sometimes undertaken using unpasteurized milk, and such products are sold at commercial markets. Because $C$. burnetii is very stable in the environment, dairy products made from unpasteurized milk represent a potential source of human infection. However, few studies have investigated the presence of $C$. burnetii in cheese.

The aim of this study was to determine the presence of $C$. burnetii in cheeses at commercial markets. For the detection of $C$. burnetii, a novel method of extracting DNA from cheese was developed for use with nested PCR. This PCRbased assay system was then used to conduct a survey of $C$. burnetii in commercial cheeses from various sources.

\section{MATERIALS AND METHODS}

Bacteria: C. burnetii Nine Mile phase II was incubated in a Buffalo green monkey (BGM) cell culture for 7-10 days in a $\mathrm{CO}_{2}$ incubator. After the medium was collected, $C$. burnetii was removed from the BGM cells by low-gravity centrifugation and washed twice with phosphate-buffered saline (PBS). After the final centrifugation, pelleted C. burnetii was resuspended in a formalin-saline solution for disinfection. Thereafter, the disinfected $C$. burnetii was washed with PBS and then resuspended in it. The quantity of $C$. burnetii was calculated as particles per milliliter by using Breed's method and the Gimenez staining method. The samples were then frozen at $-80^{\circ} \mathrm{C}$ until use. These preparations were executed in a biosafety level (BSL) 3 laboratory.

Removal of proteins and fats from the cheese samples: For DNA extraction from cheese samples, a method for effectively removing the protein and fat was developed using 3 types of cheese (soft, semihard and hard) by opti- 
mizing the conditions for each of the following steps.

1) For determining a suitable melting temperature for all cheese types, $10 \mathrm{~g}$ of cheese was incubated with $20 \mathrm{ml}$ of PBS in each water bath set at a 45,50 or $56^{\circ} \mathrm{C}$ for $30 \mathrm{~min}$. Next, the sample was homogenized by a stomacher for 1 min and then evaluated for the degree to which it had dissolved.

2) The effective separation of fat and protein from the homogenate was examined by centrifugation. The homogenate was transferred to a centrifuge tube and centrifuged at 900 or $400 \times g$ at $4^{\circ} \mathrm{C}$ for $20 \mathrm{~min}$. After the volume of the aqueous layer (middle layer) was measured, this layer was transferred to a new tube and centrifuged at $22,000 \times \mathrm{g}$ for $20 \mathrm{~min}$ at $4^{\circ} \mathrm{C}$. During the centrifugation, a precipitate was formed and pelleted. The weight of the pellets was compared with the centrifugation treatments.

3) For optimizing the re-extraction of the residual fat and protein, the melting temperature was determined. The residual fat and protein were incubated with $15 \mathrm{ml}$ of PBS in a water bath set at 45,50 or $56^{\circ} \mathrm{C}$ for $20 \mathrm{~min}$. The sample was mixed intensely for $30 \mathrm{sec}$, and the degree of dissolubility was compared with the treatments.

4) The separation of the fat and protein in the sample was examined after the centrifugation step mentioned above.

Extraction of DNA: The DNA extraction method described previously [10] was modified to enable efficient extraction from a cheese pellet. Each pellet was resuspended in $200 \mu l$ of PBS. Next, $40 \mu l$ of $20 \%$ SDS, $20 \mu l$ of proteinase $\mathrm{K}(10 \mathrm{mg} / \mathrm{m} l)$ and $6 \mu l$ of glycogen $(5 \mathrm{mg} / \mathrm{ml}$ : Ambion, Austin, TX, U.S.A.) were added. The mixture was incubated at $56^{\circ} \mathrm{C}$ for $1 \mathrm{hr}$. Five hundred microliters of NaI solution (DNA PREP; Mitsubishi Chemical Medience, Tokyo, Japan) and 1,000 $\mu l$ of isopropanol were added to the mixture and were gently mixed. The mixture was then pelleted by centrifugation for $5 \mathrm{~min}$ at $20,000 \times \mathrm{g}$ at $4^{\circ} \mathrm{C}$. The pelleted DNA was washed twice with $70 \%$ ethanol and dried. The dried pellet was dissolved in $50 \mu l$ of distilled water and used as a DNA template.

Nested PCR: C. burnetii DNA was detected by nested PCR targeting the coml [28], htp-B [26] and icd [20] genes. The primers used in the first and second PCR for each target gene are listed in Table 1.

The amplification was performed in a total volume of 50 $\mu l$ containing $5 \mu l$ of DNA template, $0.5 \mu \mathrm{M} \mathrm{MgCl}_{2}, 0.2 \mu \mathrm{M}$ dNTPs, $1 \mu \mathrm{M}$ of each primer pair and $1 \mathrm{U}$ of KOD DNA polymerase (Toyobo, Osaka, Japan). The amplification program for the OMP1-OMP2 primer pair was 36 cycles of $94^{\circ} \mathrm{C}$ for $1 \mathrm{~min}, 54^{\circ} \mathrm{C}$ for $1 \mathrm{~min}$ and $72^{\circ} \mathrm{C}$ for $1 \mathrm{~min}$. The second amplification with the OMP3-OMP4 primer pair consisted of 36 cycles at $94^{\circ} \mathrm{C}$ for $1 \mathrm{~min}, 56^{\circ} \mathrm{C}$ for $1 \mathrm{~min}$ and $72^{\circ} \mathrm{C}$ for $1.5 \mathrm{~min}$. The amplification program for the Q3-Q5 primer pair was the same as that for the OMP3-OMP4 primer pair. The second amplification with the Q4-Q6 primer pair consisted of 36 cycles at $94^{\circ} \mathrm{C}$ for $1 \mathrm{~min}, 52^{\circ} \mathrm{C}$ for $1 \mathrm{~min}$ and $72^{\circ} \mathrm{C}$ for $1 \mathrm{~min}$. The amplification program for the icd1-icd5 and the icd1N-icd2N primer pairs consisted of 25 cycles at $94^{\circ} \mathrm{C}$ for $1 \mathrm{~min}, 55^{\circ} \mathrm{C}$ for $1 \mathrm{~min}$ and $72^{\circ} \mathrm{C}$ for $2 \mathrm{~min}$. Amplification was conducted using a GeneAmp PCR System 9700 (Applied Biosystems, Carlsbad, CA, U.S.A.). The PCR-amplified products were detected by electrophoresis in a $1.5 \%$ agarose gel, stained with ethidium bromide and visualized under UV illumination at 320 $\mathrm{nm}$. A result was considered positive when all 3 target genes were successfully amplified.

Sequencing of fragments of 3 target genes: The amplified PCR products were purified using a Montage PCR Centrifugal Filter Devices kit (Millipore, Billerica, MA, U.S.A.), according to the manufacturer's instructions. Sequencing reactions were carried out using a BigDye Terminator cycle sequencing kit (Applied Biosystems). The DNA sequences of the PCR products were determined using an ABI PRISM 3130 genetic analyzer (Applied Biosystems), and nucleotide sequence data were aligned using the program ClustalW.

Detection limit: The detection limit of the nested PCR amplification was assessed by spiking $C$. burnetii particles into semihard-type shredded cheese that had been confirmed to be free of $C$. burnetii DNA by the method mentioned above. A 10-fold dilution series of frozen C. burnetii particles $\left(6.0 \times 10^{3}, 6.0 \times 10^{2}, 6.0 \times 10^{1}\right.$ and $6.0 \times 10^{0}$ particles per gram) was spiked into $10 \mathrm{~g}$ of cheese, and DNA was extracted using the method described above $(n=5)$. The nested PCR assays were then performed to determine the

Table 1. Oligonucleotides used for the detection of C. burnetii by nested PCR

\begin{tabular}{|c|c|c|c|c|c|}
\hline Target gene & & Primer & Nucleotide sequence & Size of PCR product & Reference \\
\hline \multirow{4}{*}{ com 1} & 1st PCR & OMP1 & F: 5'-AGTAGAAGCATCCCAAGCATTG-3' & & \multirow{4}{*}{ [28] } \\
\hline & & OMP2 & R: 5'-TGCCTGATAGCTGTAACGATTG-3' & $501 \mathrm{bp}$ & \\
\hline & \multirow[t]{2}{*}{ Nested PCR } & OMP3 & F: 5'-GAAGCGCAACAAGAAGAACAC-3' & \multirow{2}{*}{$438 \mathrm{bp}$} & \\
\hline & & OMP4 & R: 5'-TTGGAAGTTATCACGCAGTTG-3' & & \\
\hline \multirow{4}{*}{$h t p-B$} & 1st PCR & Q3 & F: 5'-GGCAATCACCAATAAGGGCCG-3' & \multirow{2}{*}{$501 \mathrm{bp}$} & \multirow{4}{*}{ [26] } \\
\hline & & Q5 & R: 5'-GCGGGTGATGGTACCACAACA-3' & & \\
\hline & Nested PCR & Q4 & F: 5'-TCAAGCTCCGCACTCATG-3' & \multirow{2}{*}{$325 \mathrm{bp}$} & \\
\hline & & Q6 & R: 5'-TTGCTGGAATGAACCCCA-3' & & \\
\hline \multirow{4}{*}{$i c d$} & 1st PCR & icd1 & F: 5'-CGGAGRCTCTTAGTFATGACGGA-3' & $400 \mathrm{bn}$ & \multirow{4}{*}[20]{} \\
\hline & & icd5 & R: 5'-GCAGCGCGACATTGAGCGAACG-3' & $400 \mathrm{bp}$ & \\
\hline & Nested PCR & $\operatorname{icd} 1 \mathrm{~N}$ & F: 5'-GGAGRRAACCGGAGTATCCA-3' & \multirow{2}{*}{$370 \mathrm{bp}$} & \\
\hline & & $\operatorname{icd} 2 \mathrm{~N}$ & R: 5'-ATTGAGCGAACGTATGCCAC-3' & & \\
\hline
\end{tabular}


detection limit.

C. burnetii viability test: When $C$. burnetii DNA was detected from a sample by nested PCR, the viability of $C$. burnetii was assessed by inoculating the samples into mice [21]. The refrigerated sample was treated according to the method stated above, except that the first incubation temperature was $50^{\circ} \mathrm{C}$. After centrifugation at $22,000 \times g$ for 20 $\mathrm{min}$, the precipitate was resuspended in sucrose phosphate glutamate. The sample was intraperitoneally inoculated into an immunosuppressed A/J mouse. The mouse was maintained in an isolator in a BSL 3 laboratory for 3 weeks and maintained in an immunosuppressed state by cyclophosphamide administration every 5 days. Three weeks after the inoculation, the mouse was euthanized under ether anesthesia, and the serum and spleen were collected.

For identifying the viability of $C$. burnetii, a method described elsewhere was used [18]. In the first step of examination, PCR was performed to examine whether the bacterial DNA would be amplified from the spleen, and a spleen stamp was microscopically examined. DNA was extracted from the spleen by using $1,000 \mu l$ of lysis buffer (0.5\% Nonidet P-40 [NP-40], 0.5\% Tween 20 and $10 \mathrm{mmol} /$ $l$ Tris- $\mathrm{HCl}[\mathrm{pH} 8.0])$ with $20 \mu l$ of proteinase $\mathrm{K}(10 \mathrm{mg} / \mathrm{m} l)$. After incubation of the mixture at $56^{\circ} \mathrm{C}$ for $1 \mathrm{hr}$, the mixture was heat inactivated at $95^{\circ} \mathrm{C}$ for $10 \mathrm{~min}$ and then centrifuged at $500 \times \mathrm{g}$ for $10 \mathrm{~min}$. The supernatant was used as the template for nested PCR. The spleen stamp was fixed with methanol, stained with fuchsine by the Gimenez staining method and examined under a microscope. This would have been followed by a second step of examination had the first step detected positive samples. C. burnetii viability would have been considered confirmed if all the tests were positive.

These examinations were executed in a BSL 3 laboratory. The mouse experiments were approved by the Tokyo Metropolitan Institute of Public Health animal experiment committee ethics review boards.

Screening of commercial cheese samples: A total of 147 cheese samples were collected from commercial markets in the Tokyo metropolitan area from June 2005 to December 2008. The samples included 137 natural cheeses and 10 processed cheeses. Forty-one of the 137 natural cheese samples were made from unpasteurized raw milk. One hundred and seventeen samples were imported products, mainly from France, Italy and Switzerland; 30 were domestic products.

\section{RESULTS}

Removal of protein and fat from the cheese samples: The melting temperatures of the soft and semihard cheeses did not differ over the range used in this study. However, a small amount of solid substance remained at 45 and $50^{\circ} \mathrm{C}$ in the hard cheeses. Therefore, $56^{\circ} \mathrm{C}$ was used as the melting temperature.

The separation of fat from the aqueous layer was a straightforward process because it was solidified by the low temperature $\left(4^{\circ} \mathrm{C}\right)$ during centrifugation. Among the examinations of 5 samples, the average volume of the aqueous layer was $14.8 \mathrm{ml}$ at $900 \times g$ centrifugation, and the recovery rate was $74.2 \%$. At $400 \times g$ centrifugation, the average volume of the aqueous layer was $14.5 \mathrm{ml}$, and the recovery rate was $72.6 \%$. The recovery rate of the aqueous layer at $900 \times$ $g$ was better than that at $400 \times g$. The average pellet weight was $0.53 \mathrm{~g}$ at $900 \times g$ and $0.68 \mathrm{~g}$ at $400 \times g$. The pellet weight at $900 \times g$ was lower than that at $400 \times g$. Therefore, the centrifugal force of $900 \times g$ was adopted.

For the re-extraction step, the melting conditions were the same for the residual fat and protein for all 3 cheese types.

The average volumes of the aqueous layers recovered at $900 \times g$ did not differ from those recovered at $400 \times g$ after the centrifugation for re-extraction. And the weights of the pellets were too small to measure.

Based on these results, a new method of extracting DNA from cheese was determined and is shown in Fig. 1.

Determination of the detection limit: Detection of C. burnetii DNA from the spiked cheese samples by nested PCR was performed by targeting the com $1, h t p-B$ and icd genes. The samples $(n=5)$ spiked with $6.0 \times 10^{3}$ or $6.0 \times 10^{2}$ particles per gram were always positive, as determined by nested PCR. In contrast, the samples spiked with $6.0 \times 10^{1}$ particles per gram were not consistently positive. The com 1

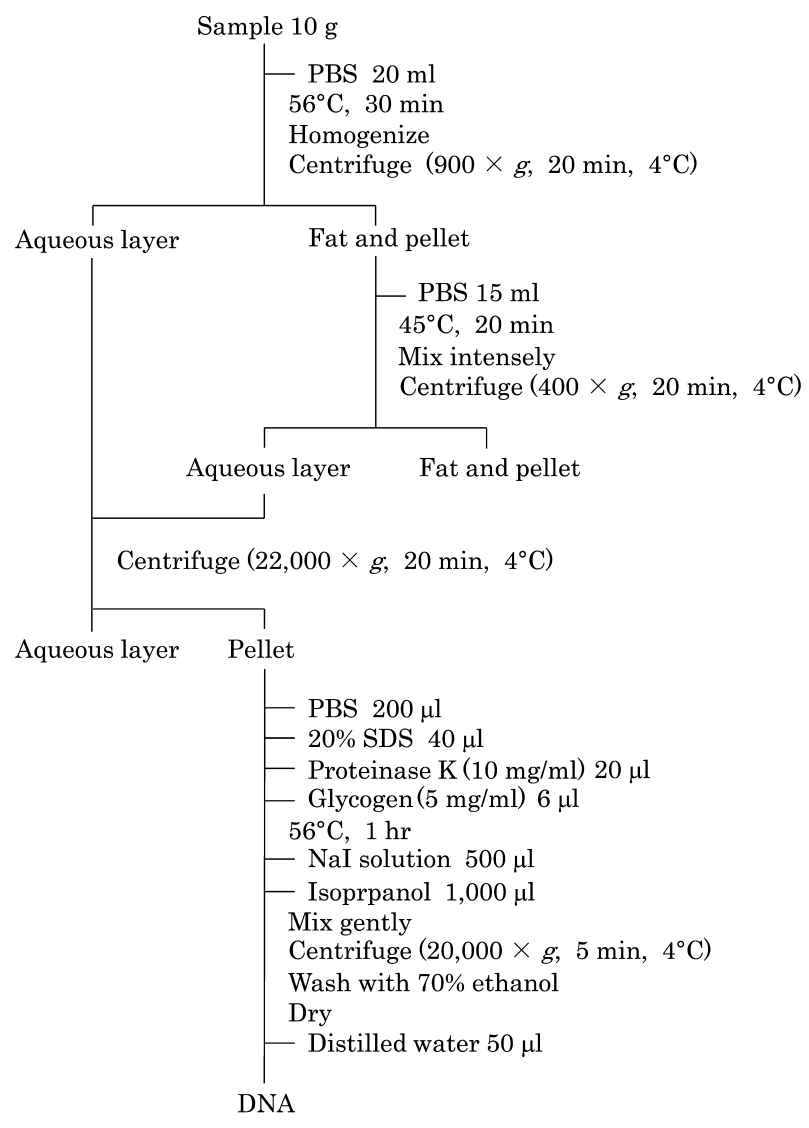

Fig. 1. Method of extracting DNA from cheese. 
nested PCR reaction detected the target gene in $100 \%(5 / 5)$ of the samples, whereas the $h t p-B$ and $i c d$ genes detected the target gene in $60 \%(3 / 5)$ and $80 \%(4 / 5)$ of the samples, respectively. For the samples spiked with $6.0 \times 10^{0}$ particles per gram, none of the genes were detected. According to the criterion that a result was positive only if all 3 target genes were amplified, a concentration of $6.0 \times 10^{2}$ C. burnetii particles per gram was determined to be the detection limit for the method.

PCR detection of $C$. burnetii DNA in commercial cheese: Twenty-eight (19.0\%) of the 147 examined cheese samples were positive for $C$. burnetii, as determined by nested PCR (Table 2). Positive samples included 20 (20.8\%) of the 96 natural cheeses made from pasteurized milk, 7 (17.1\%) of the 41 natural cheeses made from raw milk and $1(10.0 \%)$ of the 10 processed cheeses. The countries of origin for the positive samples were France (15 samples, 19.7\%), Japan (6 samples, 20.0\%) and Italy (7 samples, 50.0\%).

Sequence analysis: The 438 base pairs of the com 1 amplified fragment, the 325 base pairs of the $h t p-B$ amplified fragment and the 370 base pairs of the icd amplified fragment were successfully sequenced from 20,20 and 18 of the PCR-positive samples, respectively. Other PCR-positive samples could not be sequenced because of insufficient quantities of the amplified products. No differences in the gene sequences were found in the sequenced samples, with the exception of a point mutation in the icd gene. At position 745 of the icd gene, the guanine $(\mathrm{G})$ in the Nine Mile strain was substituted with an adenine (A) in all of the 18 PCR-positive samples.

C. burnetii viability: C. burnetii viability was determined in 28 PCR-positive samples, including 7 raw milk cheeses. In the first step of identification, all the samples were negative, as observed by nested PCR of the DNA from the mouse spleen and by the microscopic examination of the spleen stamp. Thus, although some of the cheese samples had $C$. burnetii DNA, none had viable $C$. burnetii.

\section{DISCUSSION}

In dairy cows, milk is an important route for shedding $C$. burnetii [8]. As C. burnetii cannot be cultured by artificial culturing methods, nested PCR represents a simple and sensitive screening method for detecting $C$. burnetii in food samples. PCR-positive results for $C$. burnetii in milk have been obtained in a number of countries $[11,16]$. In contrast, only a few studies have described the presence of $C$. burnetii in dairy products. Furthermore, there have been no reports of direct detection of $C$. burnetii in cheese by PCR. This study is the first one to report the detection of $C$. burnetii in cheese.

On the preparation of samples for PCR, the extraction of DNA from cheese is inhibited by fat and protein. In our method, the fats and proteins in the cheese samples were eliminated by incubating the samples at $56^{\circ} \mathrm{C}$ and by using low-gravity centrifugation at a low temperature.

On the other hand, in milk, eggs and mayonnaise, PCRbased methods have been developed for detecting C. burnetii DNA. The lowest detection limit in these studies was between 1 and $10^{3}$ particles per milliliter in bovine milk [2, $6,10,22], 10^{2}$ particles per milliliter in caprine milk [22], $10^{2}$ particles per $15 \mathrm{mg}$ and $3.2 \times 10^{1}$ particles per gram in egg yolk $[6,10]$ and $5.0 \times 10^{2}$ particles per $50 \mathrm{~g}$ in mayonnaise [23]. The detection limit described in this study $(6.0 \times$ $10^{2}$ particles per gram) is similar to that reported in milk, eggs and mayonnaise.

Campylobacter jejuni, C. coli, Escherichia coli and Listeria monocytogenes [1], Staphylococcus aureus [24], Brucella spp. [25] and Corynebacterium casei [17] have been found in dairy products by direct detection using PCR. The dairy product samples for DNA extraction weighed $0.2-2.0$ $\mathrm{g}$, and sample preparations required more than $5 \mathrm{hr}$. The DNA extraction methods described in those studies were used for small samples and involved complex procedures.

The detection limits described in those studies were 550 $\mathrm{CFU} / \mathrm{g}$ (S. aureus), $10^{2} \mathrm{CFU} / \mathrm{g}$ (Brucella $\mathrm{spp}$.) and $10^{5} \mathrm{CFU} /$ $\mathrm{g}$ (C. casei). On the other hand, as the result of optimization

Table 2. PCR Detection of C. burnetii DNA in commercial cheese

\begin{tabular}{|c|c|c|c|c|}
\hline \multirow{3}{*}{ Country } & \multicolumn{4}{|c|}{ Number of positive samples/Number of samples examined } \\
\hline & \multicolumn{2}{|c|}{ Natural cheese made from } & \multirow{2}{*}{ Processed cheese } & \multirow[b]{2}{*}{ Total (\%) } \\
\hline & Pasteurized milk & Raw milk & & \\
\hline France & $11 / 49$ & $4 / 26$ & $0 / 1$ & $15 / 76(19.7)$ \\
\hline Japan & $5 / 21$ & & $1 / 9$ & $6 / 30(20.0)$ \\
\hline Italy & $4 / 9$ & $3 / 5$ & & $7 / 14(50.0)$ \\
\hline Switzerland & & $0 / 7$ & & $0 / 7$ \\
\hline Denmark & $0 / 5$ & & & $0 / 5$ \\
\hline Australia & $0 / 4$ & & & $0 / 4$ \\
\hline The Netherlands & $0 / 2$ & $0 / 1$ & & $0 / 3$ \\
\hline New Zealand & $0 / 2$ & $0 / 1$ & & $0 / 3$ \\
\hline Germany & $0 / 2$ & & & $0 / 2$ \\
\hline Cyprus & $0 / 1$ & & & $0 / 1$ \\
\hline Greece & $0 / 1$ & & & $0 / 1$ \\
\hline Spain & & $0 / 1$ & & $0 / 1$ \\
\hline Total $(\%)$ & $20 / 96(20.8)$ & $7 / 41(17.1)$ & $1 / 10(10.0)$ & $28 / 147(19.0)$ \\
\hline
\end{tabular}


of each step of the procedure, our method was able to process larger samples than those reported and can be performed in less than $3 \mathrm{hr}$. The detection limit was $6.0 \times 10^{2}$ particles per gram, and the limit was the same or greater than the limit in other studies.

In this study, C. burnetii DNA was detected in cheese samples produced in France, Japan and Italy.

An icd gene-based differentiation study has shown that point mutations at positions 745 and 1,089 of C. burnetii DNA could be used as common markers [20]. These point mutations characterized the Nine Mile and Priscilla strains. All 18 of the analyzed DNA sequences from positive samples in the present study were divided into the Priscilla group. These results showed that $C$. burnetii DNA detected in cheese samples was different from the Nine Mile strain used as the positive control in the present study.

A recent study in France showed that 31 of 37 (83.8\%) of bulk tank milk samples tested by real-time PCR were positive for C. burnetii [7]. In Japan, 131 of 244 (53.7\%) commercial milk samples tested by nested PCR were positive for $C$. burnetii [10]. Moreover, $14.3 \%$ of bovine milk samples tested by real-time PCR were positive for $C$. burnetii in Italy [19]. The results concerning the contamination frequency of cheese samples in our study are not directly comparable to those reported for milk because of differences in sample sizes and variation. The low detection of $C$. burnetii in the cheese samples from France and Japan compared with that in the milk are consistent with the reduced or no growth of bacteria in cheeses.

The Q fever outbreak that recently occurred in the southern area of the Netherlands was considered to have originated from dairy livestock [4]. Three natural cheese samples, including 1 raw milk cheese from the Netherlands, were examined in this study, and all of them were negative for C. burnetii DNA.

Several comparative epidemiological studies have suggested that consumption of cheese increases the risk of Q fever $[5,9,15]$. Our study showed that $19.0 \%$ of commercial cheeses, including 7 samples manufactured using raw milk, were PCR positive for $C$. burnetii, but none of the $C$. burnetii cells was viable. Although, C. burnetii appears to have lost its viability in these cheeses, our study was limited by a small sample size.

The significance of the oral routes of infection remains a subject of discussion [3], and further surveys are needed to determine the risk of $C$. burnetii infection for the purpose of food hygiene. The method presented here was a very useful tool for determining the presence of $C$. burnetii in cheese samples.

\section{REFERENCES}

1. Allmann, M., Hofelein, C., Koppel, E., Luthy, J., Meyer, R., Niederhauser, C., Wegmuller, B. and Candrian, U. 1995. Polymerase chain reaction (PCR) for detection of pathogenic microorganisms in bacteriological monitoring of dairy products. Res. Microbiol. 146: 85-97.

2. Barlow, J., Rauch, B., Welcome, F., Kim, S. G., Dubovi, E. and Schukken, Y. 2008. Association between Coxiella burnetii shedding in milk and subclinical mastitis in dairy cattle. Vet. Res. 39: 23.

3. Cref, O. and Condron, R. 2006. Coxiella burnetii and milk pasteurization: an early application of the precautionary principle? Epidemiol. Infect. 134: 946-951.

4. Delsing, C. E., Kullberg, B. J. and Bleeker-Rovers, C. P. 2010. Q fever in the Netherlands from 2007 to 2010. Neth. J. Med. 68: $382-387$.

5. Fishbein, D. B. and Raoult, D. 1992. A cluster of Coxiella burnetii infections associated with exposure to vaccinated goats and their unpasteurized dairy products. Am. J. Trop. Med. Hyg. 47: $35-40$.

6. Frentz, R., Schaeren, W., Tanner, M. and Baumgartner, A. 2007. Screening of various foodstuffs for occurrence of Coxiella burnetii in Switzerland. Int. J. Food Microbiol. 116: 414 418.

7. Guatteo, R., Beaudeau, F., Joly, A. and Seegers, H. 2007. Assessing the within-herd prevalence of Coxiella burnetii milk-shedder cows using a real-time PCR applied to bulk tank milk. Zoonoses Public Health. 54: 191-194.

8. Guatteo, R., Beaudeau, F., Berri, M., Rodolakis, A., Joly, A. and Seegers, H. 2006. Shedding routes of Coxiella burnetii in dairy cows: implications for detection and control. Vet. Res. 37: 827-833.

9. Hatchette, T. F., Hudson, R. C., Schlech, W. F., Campbell, N. A., Hatchette, J. E., Ratnam, S., Raoult, D., Donovan, C. and Marrie, T. J. 2001. Goat-associated Q fever: a new disease in Newfoundland. Emerg. Infect. Dis. 7: 413-419.

10. Hirai, A., Kaneko, S., Nakama, A., Ishizaki, N., Odagiri, M., Kai, A., Sadamasu, K., Shinkai, T., Yano, K. and Morozumi, S. 2005. Investigation of Coxiella burnetii contamination in commercial milk and PCR method for the detection of $C$. burnetii from egg. J. Food Hyg. Soc. Jpn. 46: 86-92.

11. Hirai, K., Ando, M., Yamaguchi, T. and Fukushi, H., 2004. Q fever: Coxiellosis (Q netsu: Kokusierasho). Sustain. Livest. Prod. Hum. Welf. 58: 119-124.

12. Kloppert, B., Wolter, W., Zschock, M., Kabisch, D., Hamann, H. P. and Frost, J. W. 2004. Coxiella burnetii as zoonotic pathogen with special regard to food hygiene. Dtsch Tierarztl Wochenschr. 111: 321-323.

13. Komiya, T. 2004. The source and infectious route of Q fever. Antibiot. Chemother. 20: 698-705.

14. Loftis, A. D., Priestley, R. A. and Massung, R. F. 2010. Detection of Coxiella burnetii in commercially available raw milk from the United States. Foodborne Pathog. Dis. 7: 1453-1456.

15. Maltezou, H. C., Constantopoulou, I., Kallergi, C., Vlahou, V., Georgakopoulos, D., Kafetzis, D. A. and Raoult, D. 2004. Q fever in children in Greece. Am. J. Trop. Med. Hyg. 70: 540544.

16. Maurin, M. and Raoult, D. 1999. Q Fever. Clin. Microbiol. Rev. 1999: 518-553.

17. Monnet, C., Correia, L., Sarthou, A-S. and Irlinger, F. 2006. Quantitative detection of Corynebacterium casei in cheese by real-time PCR. Appl. Environ. Microbiol. 72: 6972-6979.

18. Nagaoka, H., Akiyama, M., Sugieda, M., Nishio, T., Akahane, S., Hattori, H., Ho, T., Fukushi, H. and Hirai, K. 1996. Isolation of Coxiella burnetii from children with influenza-like symptoms in Japan. Microbiol. Immunol. 40: 147-151.

19. Natale, A., Busani, L., Comin, A., De Rui, S., Buffon, L., Nardelli, S., Marangon, S. and Ceglie, L. 2009. First report of bovine Q-fever in north-eastern Italy: preliminary results. Clin. Microbiol. Infect. 15: 144-145. 
20. Nguyen, S. V. and Hirai, K. 1999. Differentiation of Coxiella burnetii isolates by sequence determination and PCR-restriction fragment length polymorphism analysis of isocitrate dehydrogenase gene. FEMS Microbiol. Lett. 180: 249-257.

21. Oda, H. and Yoshiie, K. 1989. Isolation of a Coxiella burnetii strain that has low virulence for mice from a patient with acute Q fever. Microbiol. Immunol. 33: 969-973.

22. Rodolakis, A., Berri, M., Héchard, C., Caudron, C., Souriau, A., Bodier, C. C., Blanchard, B., Camuset, P., Devillechaise, P., Natorp, J. C., Vadet, J. P. and Arricau-Bouvery, N. 2007. Comparison of Coxiella burnetii shedding in milk of dairy bovine, caprine, and ovine herds. J. Dairy Sci. 90: 5352-5360.

23. Sadamasu, K., Tabei, Y., Shinkai, T., Hasegawa, M., Kaneko, S., Hirai, A., Nakama, A., Ishizaki, N., Odagiri, M., Kamata, S., Yano, K., Kai, A. and Morozumi, S. 2006. Development of effective detection method for Coxiella burnetii in mayonnaise by real-time PCR and investigation of $C$. burnetii contamination in commercial mayonnaise in Tokyo. Food Hyg. Saf. Sci. 47: $1-8$.
24. Tamarapu, S., Mckillip, J. L. and Drake, M. 2001. Development of a multiplex polymerase chain reaction assay for detection and differentiation of Staphylococcus aureus in dairy products. J. Food Prot. 64: 664-668.

25. Tantillo, G., Dipinto, A., Vergara, A. and Buonavoglia, C. 2001. Polymerase chain reaction for the direct detection of Brucella spp. in milk and cheese. J. Food Prot. 64: 164-167.

26. To, H., Kako, N., Zhang, G. Q., Otsula, H., Ogawa, M., Ochiai, O., Nguyen, SA. V., Yamaguchi, H., Fukushi, H., Nagaoka, N., Akiyama, M., Amano, K. and Hirai, K. 1996. Q Fever pneumonia in children in Japan. J. Clin. Microbiol. 34: 647-651.

27. Tsurumi, K. 2003. Establishment of standards and requirements for milk and milk products under the food sanitation law. Food Sanit. Res. 53: 7-16.

28. Zhang, G. Q., Nguyen, S. V., To, H., Ogawa, M., Hotta, A., Yamaguchi, T., Kim, H. J., Fukushi, H. and Hirai, K. 1998. Clinical evaluation of a new PCR assay for detection of Coxiella burnetii in human serum samples. J. Clin. Microbiol. 36: 77-80. 